\title{
Effects of the maximum flow ramping rates on the long-term operation decisions of a hydropower plant
}

\author{
I. Guisández ${ }^{1}$, J.I. Pérez-Díaz ${ }^{1}$ and J.R. Wilhelmi ${ }^{1}$ \\ ${ }^{1}$ Department of Hydraulic and Energy Engineering \\ E.I. de Caminos, Canales y Puertos, Technical University of Madrid (UPM) \\ c/ Profesor Aranguren s/n, 28040 Madrid (Spain) \\ Phone/Fax number: +0034 913 366705, e-mail: i.guisandez@upm.es
}

\begin{abstract}
This paper presents a study on the influence of maximum ramping rates (MRR) on the annual operation of a real hydropower plant. For this purpose, an annual optimization model based on incremental dynamic programming (IDP) with weekly steps is used, each step being evaluated by mixed integer linear programming (MILP) on an hourly basis. The model considers hourly water inflows and energy prices, limits on reservoir level and water discharge, power generation dependence on the available head, wear and tear costs of hydro units caused by power variations, start-up and shut-down costs of hydro units, and minimum environmental flows and maximum ramping rates. The main contribution of the proposed model is the consideration of the released flow as a second state variable to define the state diagram of the problem, with the aim of guaranteeing the continuity of flow between consecutive weeks and thus the fulfilment of MRR. The results obtained in a case study with a real plant are discussed. The inclusion of the released flow as state variable does not show a significant impact in the estimated annual revenue, but certain differences observed in some periods of the year might justify its consideration in shorter time horizons.
\end{abstract}

\section{Key words}

Long-term hydro scheduling, Incremental dynamic programming, Mixed integer linear programming, Environmental constraints

\section{Introduction}

Hydroelectricy has the highest efficiency, reliability and versatility of any source of electricity and therefore has become the fourth largest source of primary energy in the world and the first one among renewable energies [1]. One of its main advantages is its ability to change the generated power quickly without incurring in significant losses, except those caused by spillage, evaporation or seepage, when at a standstill [2].
In spite of its renewable nature, several investigations indicate that hydropower plants can yield undesirable effects on the ecosystems where they are located [3]-[4]. This is the reason why many countries have developed specific policies to reduce environmental impacts caused by this power generation technology and, as a result of these initiatives, the number of constraints to which hydro scheduling is subject has increased considerably [5].

The operation of a hydropower plant is usually subject to technical, strategic and operational constraints [6]. Technical constraints usually refer to those restrictions derived from determined intrinsic properties of the plant generation equipment and hydraulic system as, for example, the maximum and minimum reservoir water levels that prevent the units from operating with low efficiencies [7]. Strategic constraints, in turn, consider commonly the tracking of longer term guidelines such as, for instance, water value curves [8]. Operational constraints can be due to different motives such as, for example, the existence of other priority uses in the reservoir [9].

Environmental constraints may be sorted within the group of operational constraints. There are various types of environmental constraints but the most common are minimum environmental flows, which force minimum values of water release, and maximum ramping rates (MRR), which impose maximum rates of change of flows (up and down).

Unfortunately, environmental constraints may cause several negative effects on hydropower plant operation. On the one hand, minimum environmental flows may reduce the water and head available to produce electricity, and, on the other hand, MRR limit its flexibility to change 
the power output [10], that is, these ramps introduce inertia in the plant operation.

A wide range of optimization techniques has been applied to determine the optimal operation of power systems since the beginning of the last century [11]. Linear programming and dynamic programming are among the most popular techniques used for reservoir system operation [12].

In addition, hybrid operation models that combine and take advantage of the best of both above-mentioned techniques have been used with remarkable success [13]. In this paper the model presented in [14] is revised and used as a basis to gain insight on the impact of the ramping rates on the long-term operation of a hydropower plant. Said model is based on discrete dynamic programming (DDP) and mixed integer linear programming (MILP) and is used to assess the impact of the above-mentioned environmental constraints on the annual revenue of a hydro plant. The DDP algorithm has an annual time horizon and uses the stored volume and weekly released volumes as state and decision variables, respectively. The MILP algorithm has a weekly time horizon and uses the hourly water discharges as decision variables; it is used to calculate the revenue associated to each weekly feasible transition within the state diagram of the DDP algorithm.

As it was discussed in [14], the solution of the DDP-MILP model proposed therein ignores continuity of flows between two consecutive weeks. Then, a heuristic method was proposed in [14] to "refine" the solution. This results in a feasible solution which satisfies MRR constraints, but it is not necessarily the optimum solution.

In the model proposed in this paper, following one of the two lines of further work proposed in [14], the continuity of flow between consecutive weeks is guaranteed by considering the hourly discharged flow as a second state variable in the annual problem, where incremental dynamic programming (IDP) is used to reduce the computational burden [15]. The weekly problem is solved by MILP as in the previous model, but each transition, is defined by the initial and final values of the stored volume and hourly discharged flow.

The paper is organized as follows. In the next section, the proposed methodology to solve the above-mentioned problems is briefly described. In Section 3, these methodologies are applied to a real hydroelectric plant under two different operating conditions, with and without ramping rates, in order to evaluate the influence of this environmental constraint on the long-term operation of a hydropower plant. Finally, main conclusions of this research are drawn in Section 4.

\section{Methodology}

Two IDP-based models are employed in this paper to analyse the influence of MRR on the long-term optimal operation of a hydropower plant. The objective function to be maximized is the annual revenue of the hydropower plant in the day-ahead electricity market. The time horizon of both models is one year and is divided into weekly stages. The first model, IDP-1, uses the stored volume as state variable, following the classical approach [16], whereas the second one, IDP-2, uses additionally the released flow as state variable.

A MILP algorithm, described in [14], is responsible for calculating the revenue associated to each weekly feasible transition within both IDP-based models. The objective function of the MILP-algorithm is to maximize the weekly revenue of the hydropower plant in the day-ahead market. This algorithm, wherein the time horizon is divided into hourly stages, according to the programming periods of the Spanish electricity market, contemplates the following aspects:

- Maximum storage capacity.

- Minimum water content of the reservoir below which it is not convenient or possible to generate power.

- Plant generation characteristic model consisting of a series of power-discharge piecewise linear curves each corresponding to a different volume in the reservoir [17].

- Maximum and minimum flows released through the bottom outlets and the spillways.

- Start-up and shut-down costs of the hydro units.

- Wear and tear costs of the hydro units caused by power variations.

- Hourly water inflows and energy prices.

- Minimum environmental flows.

- Maximum ramping rates (if there are any).

As in [14], a traditional DDP-based algorithm (hereinafter referred to as preprocess) with a simple generation characteristic is used to obtain an initial reservoir trajectory; this is considered as the trial trajectory for the IDP-1 model. An accurately discretized state diagram is used in the preprocess. Weekly revenue is calculated as the product of the weekly average energy price, the generated power (determined from the average net head and the plant operating flow) and the operating time. This time is equal to 168 hours, when the average flow released by the reservoir is equal or above the operational minimum, or reduced proportionally in other case.

A reduced state diagram (hereinafter referred to as corridor) is built around the trial trajectory of IDP-1. The corridor is composed of a maximum of three feasible states per week. Within this corridor, the reservoir trajectory that maximizes the annual revenue is obtained by solving the well-known Bellman's equation [18]. As it was above-mentioned, weekly revenue is determined by means of a MILP-based algorithm. If the obtained trajectory "touches" any border of the corridor, a new corridor is built around said trajectory with the previous discretization size; otherwise, the discretization size of the corridor is reduced. The process stops, defining the optimal policy (understood as the stored volumes at the beginning of each week, or reservoir trajectory, and the hourly released flows), once that the difference in annual 
revenue between two consecutive iterations is lower than $0.01 \%$.

In general the obtained solution contains abrupt flow changes in each transition. This unfeasibility is eliminated as suggested in [14], forcing flow continuity at each transition. Each weekly problem is recalculated by means of a similar MILP-based algorithm, where the initial and final flow are given by the estimated transition values.

The weekly stored volumes obtained with IDP-1 are used as a trial trajectory for IDP-2. The subsequent iterative procedure is similar to that of IDP-1, with the flow as additional state variable. In order to be more accurate, each optimal policiy is recalculated with a non-concave plant generation characteristic model [19].

\section{Case study}

A real hydropower plant, situated in the Northwest area of Spain, has been used to study the effects of the MRR on its long-term operation decisions. The plant is a dambased scheme; the power house is located at the toe of the dam and the water is conveyed to the turbines via three different penstocks that go through the body of the dam. The technical data of this plant were provided by the plant owner company; the historical series of water inflows and hourly energy prices (to build the average scenario) were taken, respectively, from the web pages of the Centre for Public Works Studies and Experimentation [20] (years: 1963-1965, 1966-2005) and of the Iberian Electricity Market Operator [21] (years: 1998-2011); the values of the flow ramp limits were extracted from the web page of the Miño-Sil River Basin Authority. Weekly average values of the water inflows and energy prices are shown in Figures 1 and 2. The main operation parameters of the hydropower plant are included in Table I, and the considered values of the environmental constraints, expressed in conventional units and in relative terms with respect to certain plant parameters (as in [14]), can be seen in Table II.

The IDP-based models described in Section 2 were implemented in MATLAB R2010a (each transition was solved using CPLEX under GAMS 23.3.3) on a machine running on Windows 7 with 2 threads Intel Core i5-450 M, 2.4 GHz and $4 \mathrm{~GB}$ of RAM. The characteristic parameters used in the MILP algorithm, which were determined by means of a proper sensitivity analysis, are shown in Table III.

With the above-mentioned parameters, the total computing time used for the preprocess, IDP-1 without and with MRR, and IDP-2 with MRR, were, respectively, $921 \mathrm{~s}(0.3 \mathrm{~h}), 4,335 \mathrm{~s}$ (1.2 h), 21,401 s (5.9 h) and 33,173 s (9.2 h).

From the available data, it was observed that the water level of the reservoir at the beginning of May is similar year after year. For this reason, the average stored volume at the beginning of the first week of May has been used as initial and final state of the IDP-based models.

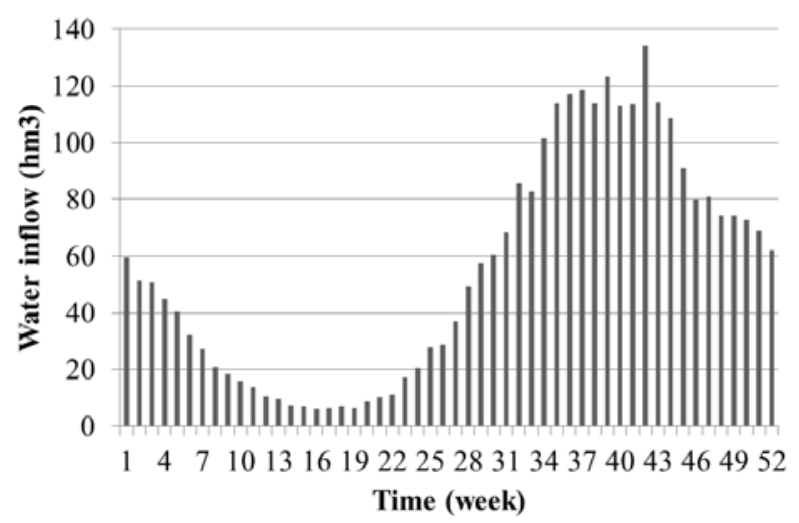

Fig. 1. Weekly water inflows of the reservoir

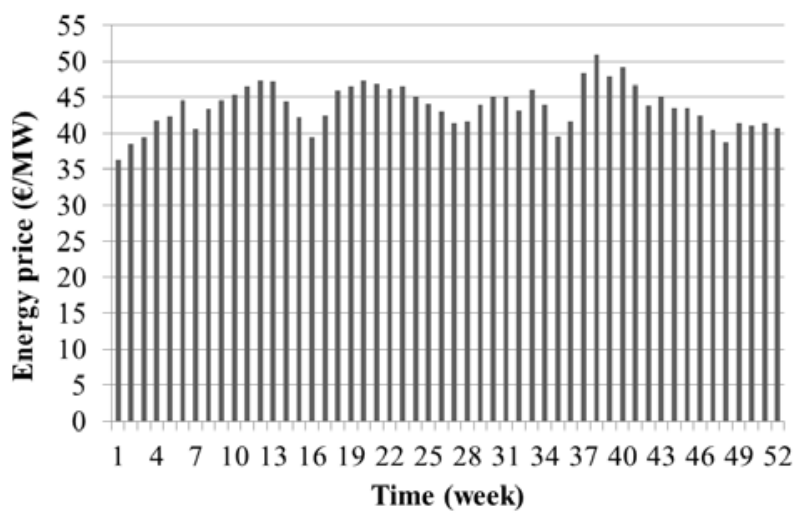

Fig. 2. Average hourly energy prices

Table I. - Main design parameters of the hydropower plant

\begin{tabular}{|c|c|}
\hline MAIN DESING PARAMETER & VALUE \\
\hline \multicolumn{2}{|l|}{ Maximum useful volume (hm3) } \\
\hline- from $15^{\text {th }}$ October to $15^{\text {th }}$ April & 536.63 \\
\hline - from $16^{\text {th }}$ April to $14^{\text {th }}$ October & 573.63 \\
\hline Maximum water elevation (masl) & 329.50 \\
\hline Minimum water elevation (masl) & 270.00 \\
\hline Tailwater elevation (masl) & 195.07 \\
\hline Number of hydro units & 3 \\
\hline Type of hydro units & Francis \\
\hline Number of penstocks & 3 \\
\hline Maximum flow (m3/s) & $279(3 \times 93)$ \\
\hline Minimum flow (m3/s) & 40 \\
\hline Maximum power (MW) & 319.7 (3x106.6) \\
\hline Minimum power (MW) & 21.9 \\
\hline
\end{tabular}

Table II. - Environmental constraints

\begin{tabular}{|c|c|}
\hline ENVIRONMENTAL CONSTRAINT & VALUE \\
\hline \multicolumn{2}{|c|}{ Minimum environmental flows $\left(\mathrm{m}^{3} / \mathrm{s} ; \%\right.$ of maximum flow) } \\
\hline - from October to December & $10.46 ; 3.75$ \\
\hline - from January to March & $24.41 ; 8.75$ \\
\hline - from April to June & $4.18 ; 1.50$ \\
\hline - from July to September & $16.74 ; 6.00$ \\
\hline \multicolumn{2}{|c|}{ Maximum ramping rates $\left(\mathrm{m}^{3} / \mathrm{s} /\right.$ day ; hours of total variation) } \\
\hline- from zero to maximum flow & $148.80 ; 45$ \\
\hline - from maximum flow to zero & $74.40 ; 90$ \\
\hline
\end{tabular}

Table III. - Characteristic parameters of the MILP algorithm

\begin{tabular}{|l|c|}
\hline \multicolumn{1}{|c|}{ CHARACTERISTIC PARAMETER } & VALUE \\
\hline Relative optimality criterion (\%) & 0.1 \\
\hline Time limit for each transition (s) & 10 \\
\hline $\begin{array}{l}\text { Gross head “covered” by each curve of } \\
\text { the generation characteristic model (\%) }\end{array}$ & 10 \\
\hline
\end{tabular}


In Figure 3, the weekly initial stored volumes of the obtained optimal policies are represented. On the one hand, this figure shows that the optimal reservoir trajectories under MRR are quite similar to the one without it, during two thirds of the year; only from September to December (weeks 19-35), MRR seem to have a significant influence on the optimal reservoir trajectory. On the other hand, this figure seems to indicate that the consideration of the flow as a state variable has a negligible impact on the optimal reservoir volume trajectory; only in a couple of weeks, differences are greater than $1 \%$.

The weekly initial flows released by the reservoir corresponding to the estimated optimal policies have been depicted in Figure 4. From this perspective, the differences are more significant. The optimal policies without and with MRR are similar to each other only during a third of the year; weeks 2-5 (May), 10-16 and 1823 (from July to September). Most of these weeks, the policies subject to MRR start with higher initial flows; likely to be able to take advantage of the usual high prices during Monday morning. In addition, it is worthy to mention that significant differences are observed between the policies under MRR (IDP-1 and IDP-2), in 18 weeks; in most of these weeks, the difference is more than $9 \%$ of the maximum flow of the plant.

In Figure 5, the power-duration curves corresponding to each policy are drawn. As it seems obvious, the operation with MRR is more continuous. It is interesting to note that, with MRR, the number of hours in operation is almost $20 \%$ greater and that it never reaches the maximum power of the plant (about $6 \%$ below). From the results shown in Figure 5, it would be coherent to think that such homogeneous power-duration curves (those with MRR) may yield a lower average efficiency in the hydro units' performance. However, as it can be seen in Table IV, the average units' efficiency is $1.1 \%$ higher than the one without MRR, and the efficiency standard deviation is $1.3 \%$ lower than the one obtained without MRR, what yields a more efficient operation.

The main values of the optimal policies have been summarized in Table IV. As it can be seen in this table, the economic impact of the MRR is almost $6 \%$ even though the energy generation is more than $2 \%$ greater when this constraint is present. It can also be noted that the improvement in the annual revenue yielded by the use of the flow as a second state variable is barely appreciable (0.2 \%). However, it has been detected that in some occasions this upgrading may achieve slightly higher values (1.14\%), for example, during the whole month of July (weeks 9-12). The evolution of the hourly flows in each optimal policy during this month has been represented in Figure 6. Finally, Table IV shows that, in addition to the above-mentioned positive effects in the units' efficiency, two more desirable effects of MRR can be highlighted: the number of start-ups and shut-downs of the hydro units is about $90 \%$ lower and the total volume discharged by the bottom outlets and the spillways are significantly lower, about one half.

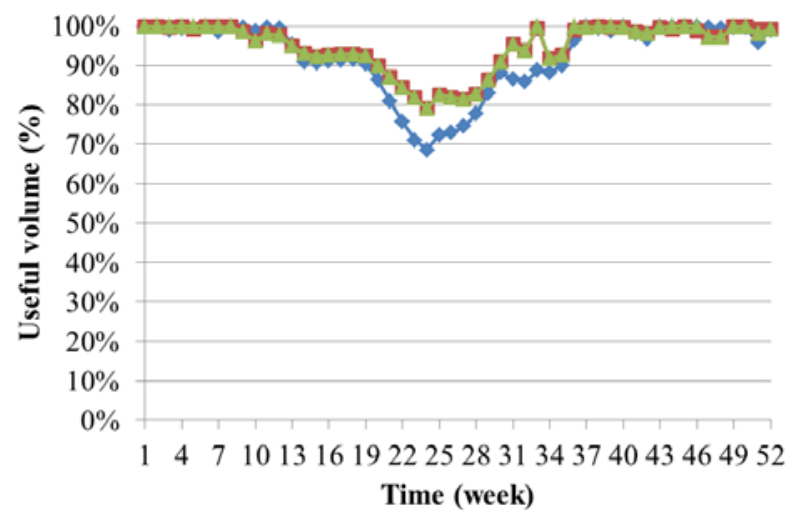

$\rightarrow$ IDP-1 without MRR - - -IDP-1 with MRR - -IDP-2 with MRR

Fig. 3. Weekly initial stored volumes of the optimal policies

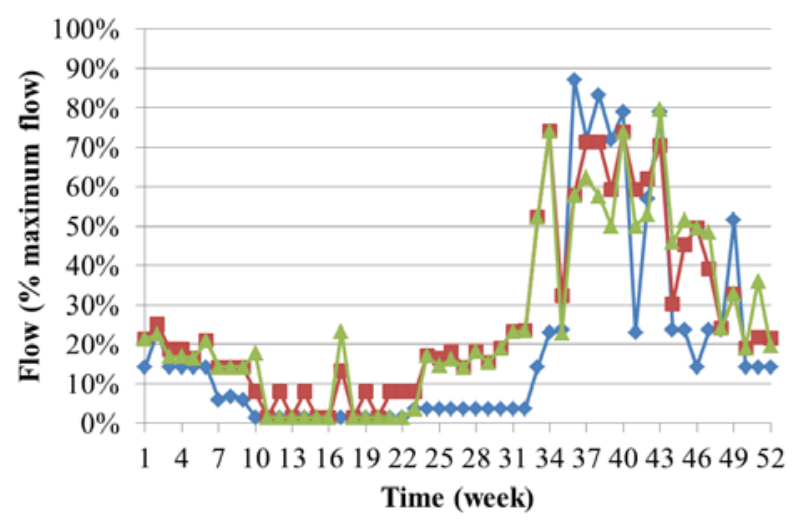

$\rightarrow-$ IDP-1 without MRR - -IDP-1 with MRR - -IDP-2 with MRR

Fig. 4. Weekly initial flows released by the reservoir in the optimal policies

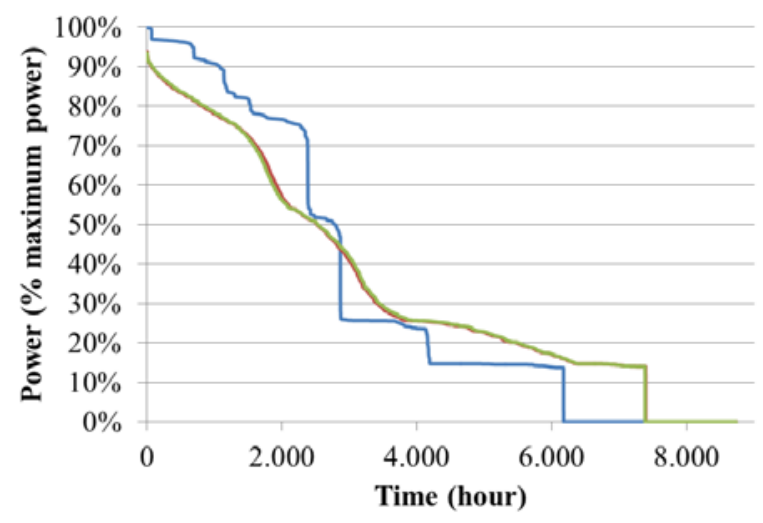

$\rightarrow-$ IDP-1 without MRR $-=$-IDP-1 with MRR - -IDP-2 with MRR

Fig. 5. Power duration-curves of the optimal policies 


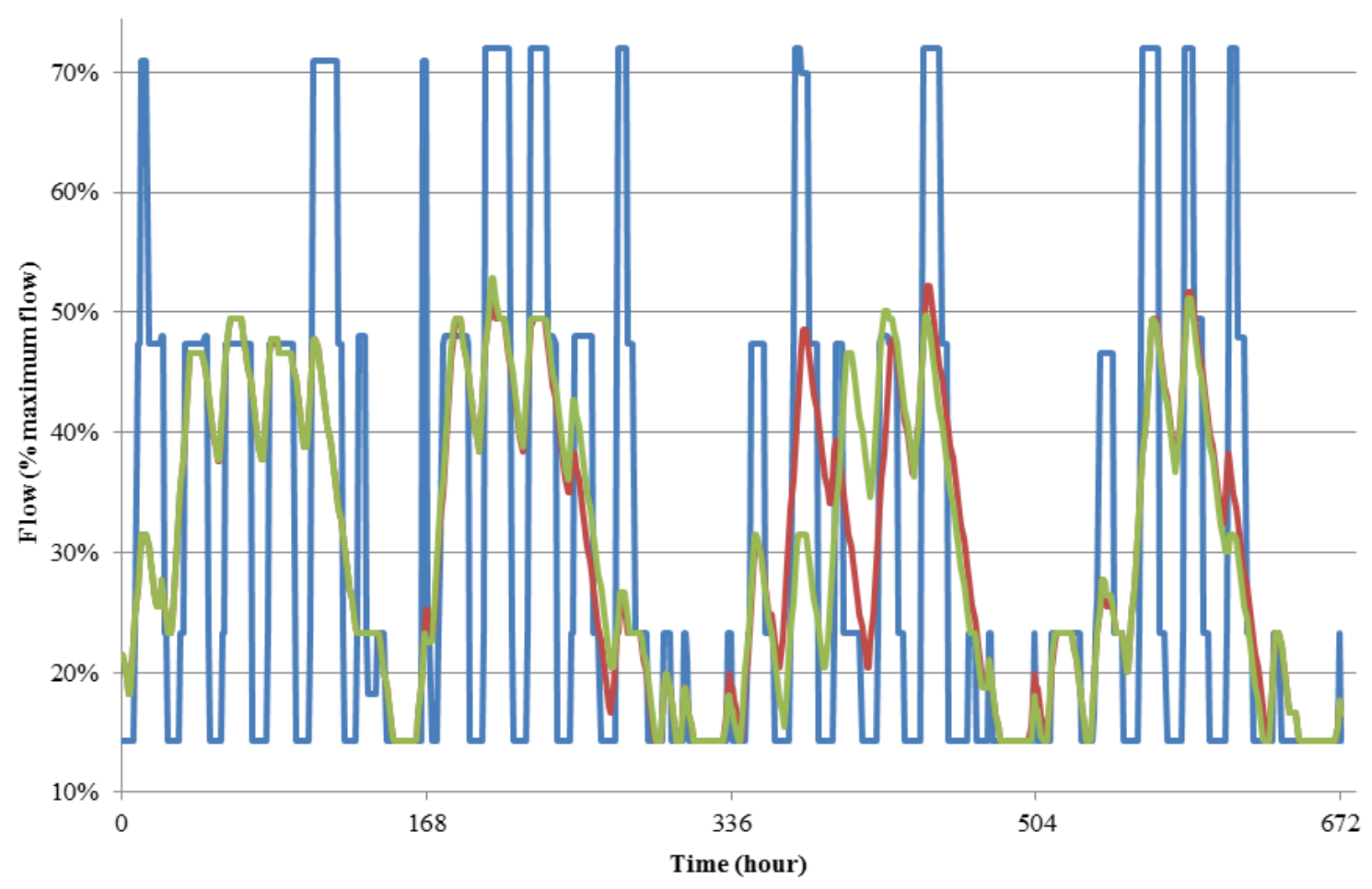

$\rightarrow$ IDP-1 without MRR - -IDP-1 with MRR $\rightarrow$ IDP-2 with MRR

Fig. 6. Hourly flows released of the optimal policies during July (weeks 9-12)

Table IV. - Main values of the optimal policies

\begin{tabular}{|l|c|c|c|c|c|c|}
\hline $\begin{array}{c}\text { OPTIMAL } \\
\text { POLICY }\end{array}$ & $\begin{array}{c}\text { REVENUE } \\
{[€]}\end{array}$ & $\begin{array}{c}\text { GENERATED } \\
\text { ENERGY } \\
{[\mathrm{GWh}]}\end{array}$ & $\begin{array}{c}\text { OPERATING } \\
\text { HOURS } \\
{[\mathrm{h}]}\end{array}$ & $\begin{array}{c}\text { AVERAGE } \\
\text { EFFICIENCY } \\
{[\%]}\end{array}$ & $\begin{array}{c}\text { START-UP } \\
\text { AND SHUT- } \\
\text { DOWNS }\end{array}$ & $\begin{array}{c}\text { SPILLAGES } \\
{\left[\mathrm{hmm}^{3}\right]}\end{array}$ \\
\hline IDP-1 without MRR & $45,278,454.08$ & 910.5 & 6,175 & $90.3 \pm 2.5$ & 1,248 & 64.8 \\
\hline IDP-1 with MRR & $42,594,900.33(-5.9 \%)$ & $933.5(2.5 \%)$ & $7,394(19.7 \%)$ & $91.4 \pm 1.2$ & $110(-91.2 \%)$ & $33.9(-47.7 \%)$ \\
\hline IDP-2 with MRR & $42,719,435.53(-5.7 \%)$ & $936.0(2.8 \%)$ & $7,384(19.6 \%)$ & $91.4 \pm 1.2$ & $96(-92.3 \%)$ & $33.3(-50.1 \%)$ \\
\hline
\end{tabular}

* The values in parentheses indicate the variation from the case without MRR.

\section{Conclusions}

Some of the effects of the maximum flow ramping rates on the long-term operation decisions of a hydropower plant have been studied in this paper. For this purpose, an annual optimal operation model has been developed. The model is based on discrete incremental dynamic programming and mixed integer linear programming. Two different versions of the model have been used: one with the stored volume as the only state variable, and the other one with the released flow as additional state variable.

The obtained results have shown that maximum ramping rates force the plant to operate much more time, more than 1,200 hours, and to earn less money, almost $6 \%$ of its annual revenue. However, the presence of this type of constraint results in slightly higher average efficiency of the plant, $1.1 \%$, many fewer start-ups and shut-downs of the hydro units, - $92.3 \%$, and significantly lower volumes released by the bottom outlets and the spillways, $-49.9 \%$.
This study seems to indicate that the idea of the refinement proposed in [14] would be adequate in a deterministic context. The obtained results show that, even though the consideration of the released flow as state variable does not have a significant impact in the estimated annual revenue in a deterministic context, certain differences obtained in determined periods of the year might justify its consideration in shorter time horizons. One option would be to use a look-ahead period of a few weeks, beyond the decision horizon for the weekly hydropower scheduling.

\section{References}

[1] Egré, D., Milewski, J. C., "The diversity of hydropower projects". Energy Policy, vol. 30, no. 14, pp. 1225-1230, 2002.

[2] Weedy, B. M., Electric power systems, John Wiley \& Sons Ltd, London, England (2012), pp. 8.

[3] Eckberg, D. K., "Cumulative impacts of hydropower development under NEPA". Environmental Law, vol. 16, pp. 673-963, 1986. 
[4] Trussart, S., Messier, D., Roquet, V., Aki, S., "Hydropower projects: a review of most effective mitigation measures". Energy Policy, vol. 30, no. 14, pp. 1251-1259, 2002.

[5] Kosnik, L., "Balancing environmental protection and energy production in the Federal hydropower licensing process". Land Economics, vol. 86, no. 3, pp. 444-466, 2010.

[6] Pérez-Díaz, J. I. and Wilhelmi, J. R., "Assessment of the economic impact of environmental constraints on short-term hydropower plant operation", Energy Policy, vol. 38, no. 12, pp. 7960-7970, 2010.

[7] Guise, J. W. B., Flinn, J. C., "The allocation and pricing of water in a river basin". American Journal of Agricultural Economics, vol. 52, no. 3, pp. 411-421, 1970.

[8] Reneses, J., Baíllo, A., Centeno, E., Ventosa, M., Rivier, M., Ramos, A., "Strategies to fulfill medium-term objectives through short-term operation in competitive power markets". In: Power tech conference, IEEE, Bologna, Italy, 23-26 June 2003.

[9] Kumar, N., Baliarsingh, F., "Folded dynamic programming for optimal operation of multireservoir system". Water Resources Management, vol. 17, no. 5, pp. 337-353, 2003.

[10] Harpman, D. A., "Assessing the short-run economic cost of environmental constraints on hydropower operations at Glen Canyon dam", Land Economics, vol. 75, no. 3., pp. 390-401, 1999.

[11] Farhat, I. A., El-Hawary, M. E., "Optimization methods applied for solving the short-term hydrothermal coordination problem". Electric Power Systems Research, vol. 79, no. 9, pp. 1308-1320, 2009.

[12] Nandalal, K. D. W., Bogardi, J. J., Dynamic programming based operation of reservoirs. Applicability and limits, Cambridge University Press, Cambridge, England (2007), pp. 36.

[13] Grygier, J. C. and Stedinger, J. R., "Algorithms for optimizing hydropower system operation", Water Resources Research, vol. 21, no. 1, pp. 1-10, 1985.

[14] Guisández, I., Pérez-Díaz, J.I. and Wilhelmi, J.R., "Assessment of the economic impact of environmental constraints on annual hydropower plant operation”, Energy Policy, vol. 61, pp. 1332-1343, 2013.

[15] Bernholtz, B. and Graham, L. J., "Hydrothermal Economic Scheduling Part 1. Solution by Incremental Dynamic Programing". IEEE Transactions on Power Apparatus and Systems, vol. 79, no. 3, pp. 921-929, 1960.

[16] Yakowitz, S., "Dynamic programming applications in water resources". Water Resources Research, vol. 18, no. 4, pp. 673696, 1982.

[17] Borghetti, A., D'Ambrosio, C., Lodi, A., Martello, S., “An MILP approach for short-term hydro scheduling and unit commitment with head-dependent reservoir". IEEE Transactions on Power Systems, vol. 23, no. 3, pp. 1115-1124, 2008.

[18] Bellman, R., "The theory of dynamic programming". Bulletin of the American Mathematical Society, vol. 60, no. 3, pp. 503-515, 1954.

[19] Conejo, A. J., Arroyo, J. M., Contreras, J., Villamor, F. A., "Self-scheduling of a hydro producer in a pool-based electricity market". IEEE Transactions on Power Systems, vol. 17, no. 4, pp. 1265-1272, 2002.

[20] Centre for Public Works Studies and Experimentation. Water inflows data (Online). Available from: \{http://hercules.cedex.es/anuarioaforos/default.asp $\}$

(accessed on: 17.01.14).

[21] Iberian Electricity Market Operator. Market results (Online). Available from:

\{http://www.omel.es/files/flash/ResultadosMercado.swf\}

(accessed on: 17.01.14). 